\title{
Effects of different hospital catering systems on sensorial degradation of foods provided to elderly patients in the UK
}

\author{
Y. Mavrommatis ${ }^{1}$, L. Methven ${ }^{1}$ and M. A. Gosney ${ }^{2}$ \\ ${ }^{1}$ Department of Food and Nutritional Sciences, University of Reading, Whiteknights, RG6 6AP, UK and ${ }^{2}$ Clinical Health \\ Sciences, University of Reading, London Road, Reading, RG1 5AQ, UK
}

Hospital patients over the age of 80 have five times higher undernutrition prevalence than patients under the age of 50 , and $60 \%$ of older patients are at risk of becoming malnourished, or their situation deteriorating ${ }^{(1)}$. The aim of the project was to investigate whether the processes that take place between food production and meal consumption by patients (food regeneration) affect the sensorial quality of hospital food. The effects of these processes on food sensorial quality were evaluated within the two main hospital catering systems, the in-house and the cook/chill system.

Both catering systems were investigated based on observations performed at two NHS hospitals in England. In each case, an expert sensory panel $(n$ 15) was provided with foods before and after regeneration. The investigated foods (Table 1$)$ were selected from the hospitals' menus based on their popularity and susceptibility to sensorial degradation. Scores of sensorial attributes (food appearance, odour, taste, flavour, mouthfeel, after effects and temperature) were recorded on visual analogue scales. Within each catering system, differences in sensorial attributes between the untreated and the regenerated versions of the same food were identified using ANOVA and principal component analysis.

Results showed that food regeneration in the in-house, but not in the cook/chill system, resulted in consistently higher temperatures compared to the untreated meals $(P<0.001)$. Certain sensorial attributes, such as after effects, appearance and mouth-feel were also affected depending on the food and the catering system (Table 1). In the in-house system, the overall sensorial effects due to food regeneration were not greater than the day-to-day variation within the system (results not shown).

\begin{tabular}{|c|c|c|c|c|}
\hline Food & Attribute & Regenerated & Untreated & Significance \\
\hline $\begin{array}{l}\text { Lamb Pie } \\
\text { Chocolate sponge cake }\end{array}$ & $\begin{array}{l}\text { In-house catering system } \\
\text { Watery (after-effect) } \\
\text { Seasoning (Flavour) } \\
\text { Blistery (appearance) } \\
\text { Soft pastry (mouthfeel) } \\
\text { Skin (appearance) }\end{array}$ & $\begin{array}{l}42(5.7) \\
28(5.5) \\
76(4.1) \\
62(5.6) \\
53(5.1)\end{array}$ & $\begin{array}{l}30(4.1) \\
37(5.9) \\
46(6.5) \\
46(5.8) \\
38(4.7)\end{array}$ & $\begin{array}{c}0.021 \\
0.028 \\
<0.001 \\
0.0147 \\
0.049\end{array}$ \\
\hline $\begin{array}{l}\text { Beef casserole } \\
\text { Cauliflower cheese } \\
\text { Fish in parsley sauce } \\
\text { Lamb dumplings }\end{array}$ & $\begin{array}{l}\text { Cook/chill catering system } \\
\text { Drying (after-effect) } \\
\text { Cheese (flavour) } \\
\text { Creamy (smell) } \\
\text { Creamy (mouthfeel) } \\
\text { Crunchy (mouthfeel) }\end{array}$ & $\begin{array}{c}30(2.6) \\
40.3(3.3) \\
20.7(2.1) \\
26.2(2.4) \\
15(3.2)\end{array}$ & $\begin{array}{l}32(2.8) \\
31.6(3.2) \\
26.7(2.9) \\
32.8(2.3) \\
36(3.8)\end{array}$ & $\begin{array}{c}\text { Not significant } \\
0.028 \\
0.012 \\
0.009 \\
<0.001\end{array}$ \\
\hline
\end{tabular}

These results suggest that the food regeneration, which takes place in hospitals with an in-house or a cook/chill catering system, leads to the degradation of certain sensorial attributes. Some, but not all of these effects, may be linked to the high food temperature and resulting condensation. It is unlikely, however, that the detected effects act as main drivers of food palatability and acceptance.

Part of mappmal study sponsored by New Dynamics of Ageing. The authors are in gratitude to the Royal Berkshire NHS Trust and Newcastle NHS Trust catering departments for their invaluable support and to the panellists at the Sensory Science Centre (University or Reading).

1. Age Concern (2006). Hungry to be Heard. The Scandal of Malnourished Older People in Hospital. London: Age Concern. 